\title{
PRECEDENTE, ANALOGÍA Y RAZONES PARA ACTUAR. COMENTARIOS SOBRE LA PROPUESTA DE FREDERICK SCHAUER ${ }^{*}$
}

\author{
PRECEDENT, ANALOGY AND REASONS FOR ACTION. \\ COMMENTS ON THE IDEAS OF FREDERICK SCHAUER
}

Abdón Mauricio RojAs MARRoquín**

\section{Resumen:}

Para buena parte de la literatura jurídica — con la que estoy particularmente de acuerdo-, el uso y seguimiento de sentencias en casos futuros es prioritariamente un asunto de analogías. Sin embargo, el reconocido profesor Frederick Schauer, en varios de sus textos, ha puesto con buenos argumentos en tela de juicio esta idea. De acuerdo con su interpretación, seguir el precedente es algo sustancialmente distinto al razonamiento analógico. En este artículo se intenta problematizar esta tesis a partir de cuatro diferencias analíticas que considero fundamentales: principios-reglas; intención comunicativa-recurso lingüístico; razones internas-externas, y razones excluyentes-concluyentes. Al interior de cada una de ellas, la tesis de la separación propuesta por Schauer, parecería fracasar.

\section{Palabras clave:}

Precedente, analogía, razones para actuar, razones excluyentes, razones concluyentes.

\section{Abstract:}

For a large part of the legal literature, with which I am particularly in agreement, the use and follow-up of judicial decisions in future cases is primarily a matter of analogies. However, the well-known professor Frederick Schauer,

Artículo recibido el 2 de marzo de 2020 y aceptado para su publicación el 16 de septiembre de 2020.

** Director de la Facultad de Derecho y Ciencias Sociales de la Universidad ICESI, correo: amrojas@icesi.edu.co, ORCID: https://orcid.org/0000-0002-4934-9882. 


\section{ABDÓN MAURICIO ROJAS MARROQUÍN}

in several of his studies and publications, has put this idea at risk with good arguments. According to his interpretation, following the precedent is something substantially different from analogical reasoning. In this paper, we try to problematize his thesis from four analytical perspectives that I consider essentials: principles-rules; communicative intentions-linguistic tool; internalexternal reason; and excluding-conclusive reasons. Within them, the thesis of separation proposed by Schauer would seem to fails.

\section{Keywords:}

Precedents, Analogy, Reasons for Action, Exclusionary Reasons, Conclusive reasons. 
PRECEDENTE, ANALOGÍA Y RAZONES...

SumARIo: I. Introducción. II. Precedente y analogía: ¿principios hermenéuticos? III. Propósito comunicativo vs. recurso comunicativo. IV. Razón interna vs. razón externa. V. Seguimiento del precedente y razonamiento analógico: ¿Razones excluyentes o razones incluyentes? VI. La obligatoriedad del precedente y la "verdad" como razón para seguirlo. VII. Conclusiones. VIII. Referencias.

\section{INTRODUCCIÓN}

El notable trabajo del profesor Frederick Schauer pone de presente una serie de buenos argumentos para poder diferenciar entre el uso de una analogía y el uso de un precedente judicial. ${ }^{1}$ En su opinión, la finalidad del precedente es, fundamentalmente, imponer la restricción que surge de tener que seguir el mismo curso de acción de un evento anterior, pese a que la persona que está obligada a hacerlo piense ahora que fue equivocado o incorrecto. Quien realiza una analogía, a contrapelo, desea usar el evento anterior como ejemplo de lo que considera adecuado, útil o correcto decir, a efectos de iluminar un punto sobre el que quiere argumentar o decidir. En conse-

1 Me refiero fundamentalmente al siguiente texto: Schauer, Frederick, "Why precedent in law (and elsewhere) is not totally (or even substantially) about analogy", Perspectives on Psychological Science, 3(6), 2008, pp. 454-460. No desconozco otras contribuciones del autor en las que pueden existir puntos de vista adicionales sobre el precedente: Schauer, Frederick, "Precedent", Stanford Law Review, 1987, pp. 571-605; Schauer, Frederick, Las reglas en juego, Madrid, Marcial Pons, 2004; Schauer, Frederick, "Has Precedent Ever Really Mattered in the Supreme Court", Ga. St. UL Rev., 24, 2007, pp. 381-401; Schauer, Frederick, The Force of Law, Harvard University Press, 2015. A pesar de los múltiples matices de todos sus textos, se mantiene en mi opinión el mismo punto sobre la fuerza normativa del Precedente, que la plantea en términos distintos al razonamiento analógico. Mi objetivo, en consecuencia, es discutir y llevar al extremo un argumento del autor, mas no hacer un balance de todo el conjunto de su teoría. Es decir, no pretendo desautorizar a Schauer, sino asumir críticamente un argumento - llevándolo al extremo- que de forma excepcional ha planteado y ha acompañado la mayor parte de su teoría. 
cuencia, la analogía carece del carácter restrictivo y vinculante que Schauer encuentra en el precedente. ${ }^{2}$

Después de todo - diría el autor-, existe una considerable divergencia entre (i) tener que seguir un curso de acción y (ii) querer seguirlo a efectos de argumentar o decidir mejor en la actualidad. Bajo este entendido, ha señalado que en el razonamiento analógico existe, por lo general, una libertad del intérprete para elegir "la fuente" o el antecedente que se quiere usar; ello en razón de que se estima que sirve a propósitos orientadores o informativos. En el precedente, en cambio, el intérprete se encuentra compelido a un hecho histórico respecto del cual tiene vedado - o al menos para lo cual resulta intrascendente- expresar sus puntos de vista acerca de cómo la cuestión debió ser decidida. En una palabra: no es lo mismo tener que hacer algo, que querer hacerlo.

Ciertamente los ejemplos usados por el profesor Schauer son inteligentes e iluminadores. Naturalmente, cuando un niño demanda de sus padres ser tratado con la misma licencia y consideración con la que fue conducido su hermano mayor en circunstancias similares, está planteando su reclamo en terrenos para los cuales resulta francamente irrelevante lo que los padres consideren ahora al respecto. Bien pudieron modificar su opinión, pero ese es un asunto menor para quien sólo tiene en mente exigir el cumplimiento del precedente. ${ }^{3}$ A su turno, cuando los juristas reprochan a los magistrados de una Corte de justicia por no seguir un precedente, realmente están señalando, en opinión de Schauer, que con independencia de si es-

2 Esta idea no es exclusiva del profesor Schauer. Los importantes ejemplos de los trabajos de Grant Lamond y Sandra Gómora, son muestra de la potencia que tiene la tesis de separación del precedente respecto de la analogía. Aunque con matices diferentes, ambos comparten la idea de que estas dos figuras del razonamiento jurídico, se mueven en planos normativos distintos. Véase Lamond, Grant, "Precedent and Analogy in Legal Reasoning", en Zalta, Edward N. (ed.), The Stanford Encyclopedia of Philosophy, 2016, disponible en: https://plato.stanford.edu/archives/ spr2016/entries/legal-reas-prec/; Gómora Juárez, S., "La ejemplaridad y proyección del precedente”, Problema. Anuario de Filosofía y Teoría del Derecho, núm. 12, 2018, pp. 199-238.

3 Es extraño que en el ejemplo de Schauer no sea algo importante que los padres puedan decirle a su hijo que han cambiado de opinión por buenas razones y justamente por la experiencia obtenida. 
PRECEDENTE, ANALOGÍA Y RAZONES...

tán de acuerdo con lo resuelto en el pasado, tienen la obligación de seguir ese mismo camino de acción, y lejos están de poder considerar a la sentencia anterior como un simple ejemplo orientador.

$\mathrm{Si}$, supongamos, el joven del ejemplo formulado por Schauer hubiera expresado a sus padres que de no contar con el mismo tratamiento recibido por su hermano mayor, se sentiría tan discriminado como los americanos afrodescendientes en relación con su sistema judicial en el siglo XIX; entonces le asiste razón al profesor estadounidense al sostener que se estaría haciendo, en esta última afirmación, algo sustancialmente diferente de exigir el acatamiento de un precedente. En efecto: el joven desea plantear la analogía con los afrodescendientes tan solo para iluminar lo más posible su punto de vista. Más claramente: desea evidenciar el padecimiento que aqueja a quienes reciben, sin mayores razones, un trato discriminatorio de quien, dado el poder de decisión sobre sus acciones, debería tratar con igualdad a sus administrados. Acá el uso de la fuente analógica sirve más para ilustrar la semejanza entre el padre y el juez, así como aquella configurada entre los sentimientos de indignación que padecen las personas que son discriminadas injustamente.

Vistas así las cosas, parece que el punto de Schauer estaría plenamente justificado. Sin embargo, me parece que hay algo en sus presupuestos que vale la pena reexaminar. Lo haré de la mano de cuatro categorías analíticas, a saber: (i) diferencia entre principios y reglas; (ii) diferencia entre la intención comunicativa y el recurso comunicativo; (iii) la diferencia entre las razones externas y las razones internas; y, finalmente, (iv) la diferencia entre razones concluyentes y razones excluyentes. Las dos primeras quisiera abordarlas muy rápidamente, ya que son las dos últimas las que, a decir verdad, me interesan de manera sobresaliente. ${ }^{4}$

4 Como debe haber quedado claro ya, pues así lo he indicado desde el mismo resumen del texto, acojo la tesis de que el precedente judicial es un tema de analogías. Es decir, que analogía y precedente no se distinguen en la forma en que lo pretenden autores como Schauer y Lamond, en especial el primero de ellos, de quien uso sus argumentos centrales. Y la expresión "analogía”, es tomada en un sentido general, como el argumento que busca que un caso actual sea tratado relativamente de la misma manera (o con la misma regla) a como fue tratado un caso anterior, porque existen buenas razones para sostener que tienen semejanzas significativas. 


\section{PRECEDENTE Y ANALOGÍA: ¿PRINCIPIOS HERMENÉUticos?}

Existe un sentido trivial en que el seguimiento del precedente y el razonamiento analógico podrían, aparentemente, diferir. Podría sostenerse, en gracia de discusión, que efectivamente se presenta en algunos sistemas jurídicos un principio que ordena atender a lo dicho en el pasado por la jurisprudencia. Un principio de esta naturaleza podría estar formulado de múltiples maneras, desde luego. No obstante ello, a decir verdad, cualquiera que sea el enunciado elegido (mejor o peor articulado, quiero decir) podríamos resumirlo de la siguiente manera: "debes seguir y/o respetar los precedentes judiciales".

Pues bien: se supone - equivocadamente, creo yo- que es extraño hallar una expresión deóntica equivalente para las analogías. Aparentemente no suelen encontrarse principios que señalen cosas como: "debes hacer analogías". De modo tal que, de ser esto correcto, seguir el precedente y razonar analógicamente podrían estar en dimensiones normativas diferentes. Podría pensarse, para hilar más fino, que el seguimiento de los precedentes es, ante todo, un "principio" acogido por un buen número de sistemas jurídicos. Sería un mandato genérico de deber ser que prescribe una pauta general de acción. La analogía, en cambio, sería una regla.

Por consiguiente, si se llegare a aceptar que el seguimiento del precedente es en términos prescriptivos un principio, al tiempo que la analogía es una regla de razonamiento lógico, nuevamente parece que el punto de Schauer estaría justificado. No obstante, este razonamiento tiene un defecto evidente. Veamos: cualquier enunciado prescriptivo, en la forma de principios o de reglas, puede ser estructurado a partir de los enunciados hipotéticos condicionales del tipo "si X (antecedente), entonces haz Y (consecuente deóntico)".

Es plausible llegar a un acuerdo en el sentido de que la única diferencia - que tal vez puede ser la más - relevante, entre una re-

En otro escrito he querido explicar con mayor nivel de detalle la estructura de este tipo de razonamiento. Véase Rojas Marroquin, Abdón, "La fuerza ilocutiva y los efectos perlocutivos en el análisis estático de sentencias judiciales", Revista de Derecho (Valdivia), 30(2), 2017, pp. 9-30. 
gla y un principio, desde el punto de vista de su estructura lógica, ${ }^{5}$ residiría por los lados del antecedente (indicación del hecho condicionante). La opinión que adscribo indicaría que, a diferencia de las reglas, los principios carecen totalmente del antecedente (son enunciados hipotético condicionales incompletos). Debo conceder, sin embargo, que para muchos teóricos los principios no siempre carecen de antecedente sino que este es más bien abierto e indeterminado, en comparación del que contienen las reglas. En mi modesta opinión, la diferencia entre estos dos tipos de normas no puede depender del carácter cerrado o abierto de su antecedente, pues parece bastante obvio que la determinación de ello depende de la decisión interpretativa de dar por exhaustivos/precisos o enunciativos/ vagos los supuestos de hecho de un enunciado hipotético condicional, razón por la cual no podría considerarse como una característica que pertenezca a su estructura lógica a priori. ${ }^{6}$

Al margen de la anterior discusión, en lo que existe un acuerdo más o menos estable es en que las reglas de ordinario sí poseen antecedentes, ${ }^{7}$ de modo tal que además de indicar cuál es la acción debida (consecuente), también trae consigo la enunciación del hecho en virtud del cual se produce dicha consecuencia jurídica. Los principios, por lo contrario, sólo nos indican el deber ser (consecuente). En ese orden de ideas, los principios requerirían de procesos de construcción de su antecedente; o procesos de concreción, en opinión de quienes acogen la idea de carácter abierto de antece-

5 Hago la salvedad por cuanto para muchos autores existiría también una diferencia sobre el nivel de importancia axiológica que tienen estas normas; o en cuanto al tipo de derrotabilidad que tienen unas y otras. Véase Guastini, Riccardo, Interpretar y argumentar, Centro de Estudios Políticos y Constitucionales, 2014, Cap. V, pp. 183 y ss.; también Bäcker, Carsten, "Reglas, principios y derrotabilidad”, DOXA, Cuadernos de Filosofía del Derecho, núm. 37, 2014, pp. 31-44.

6 Lo mismo ocurre con la supuesta mayor importancia axiológica de los principios por sobre las reglas. El carácter fundamental de un enunciado depende de una decisión interpretativa. Guastini, op. cit., pp. 190 y 191.

7 Así, mientras la función del principio consiste en fomentar un valor, a partir de una pauta de acción general; la función de la regla consiste, a veces, en concretar dicho mandato genérico al nivel de un enunciado hipotético condicional completo; y en ese sentido, podrían ser entendidas como formas concretas de realización de los principios. 
dente para el principio, repito. Vale decir, los principios exigen, para que puedan ser seguidos, de procesos interpretativos que los conduzcan hacia la categoría de las reglas. ${ }^{8}$

Repárese, entonces, en que el consecuente deóntico bajo la forma "debes seguir los precedentes judiciales", en absoluto contiene un antecedente que determine los hechos condicionantes bajo los cuales este mandato debe realizarse. En cambio, la analogía se presenta normativamente como - prioritariamente- una regla, tal cual acontece en el ordenamiento jurídico colombiano, por poner un ejemplo: "Cuando no hay ley exactamente aplicable al caso controvertido (antecedente), se aplicarán las leyes que regulen casos o materias semejantes... (consecuente)". (Artículo 8, ley 153 de 1887).

Empero, bien vistas las cosas, parece claro que la regla del razonamiento analógico podría funcionar, justamente, para construir/concretar (según sea el caso) el antecedente del cual carece el mandato deóntico de aplicación de los precedentes. Me explico: bien podría decirse "cuando las circunstancias de hecho de los casos sean análogas, deben seguirse los precedentes". Y, por lo tanto, no podría diferenciarse entre el precedente y la analogía de forma significativa, a partir de su estructura lógico-normativa. En puridad, la analogía sería la forma concreta de materialización del principio que ordena seguir los precedentes. Vale decir, es la forma de hacerlo. Luego, no serían cosas sustancialmente distintas como lo afirma Schauer.

Pero hay algo más: es innegable que la pauta genérica que más arriba se presentó en los términos prescriptivos de un principio ("debes seguir los precedentes judiciales"), fue un movimiento deliberado por presentar deónticamente al seguimiento del precedente en el consecuente y no en el antecedente del enunciado condicional. Sin embargo, bien puede trastocarse este orden, indicando, por poner algún ejemplo, lo siguiente: "deben respetarse los principios de igualdad y de seguridad jurídica (consecuente), siguiendo los prece-

8 Es más o menos eso lo que entiende Riccardo Guastini por el proceso de "concreción" de los principios. Literalmente indica lo siguiente: "Una norma "genérica" -y por tanto un "principio" - es... una norma que: (a) por un lado, exige la formulación de otras normas - que la "concreten", que posibiliten su "aplicación" o "ejecución”- sin las cuales no sería apta para resolver casos concretos”, Ibidem, p. 189. 
PRECEDENTE, ANALOGÍA Y RAZONES...

dentes judiciales (antecedente)"; situación en la cual el seguimiento del precedente queda situado ahora en el nivel de la regla de construcción/concreción del principio —de igualdad y seguridad jurídica, para este caso-, lugar reservado en los párrafos anteriores sólo para la analogía. Y en ese sentido, una vez más, ninguna diferencia sustancial aflora entre el precedente y la analogía como lo suponía Schauer.

De manera tal que, tanto la analogía como el seguimiento del precedente pueden estar ubicados indistintamente en cualquiera de los extremos de la estructura de las disposiciones normativas, según se decida subjetivamente.

Es cierto que Schauer no se detuvo concretamente en la anterior y eventual diferenciación. Quiero insistir en que no intento evaluar críticamente a un autor desde el conjunto sistemático de toda su producción teórica, sino únicamente problematizar un argumento en particular que ofreció en un determinado momento. Además, sospecho que valía la pena desatender esta diferencia analítica cuanto antes, en consideración del lector acostumbrado a separar los distintos tipos de normas. Por cierto, vale la pena también avanzar rápidamente en la siguiente aclaración:

\section{Propósito COMUNICATIVO VS. RECURSO COMUNICATIVO}

Una segunda y rápida observación que valdría la pena examinar, consiste en no pasar por alto la diferencia - también trivial, por cierto- existente entre el propósito comunicativo y el recurso comunicativo. Y dentro del primero, es bastante obvio que deberíamos diferenciar los diversos propósitos comunicativos con los cuales se usan dichos recursos (su fuerza ilocutiva).

Naturalmente, disponer de un ejemplo o realizar una comparación para iluminar una idea, es distinto de usar un ejemplo o hacer una comparación para impulsar la acción. Lo uno y lo otro dependen más de la intención comunicativa del hablante (y de su fuerza ilocutiva), y no de la estructura lógica interna del recurso lingüístico (ejemplo o comparación). La intención comunicativa, si se quiere, es más una cuestión instalada al interior de los terrenos de la pragmá- 
tica lingüística, que una vinculada a la estructura sintáctica del lenguaje. Parece claro que el contexto de enunciación de un acto de habla es algo diferente del acto de habla mismo, aunque naturalmente lo uno y lo otro se entrecruzan sustancialmente.

Supongamos que en un proceso judicial un juez indica lo siguiente:

"No es de recibo el planteamiento del señor abogado "A", en el sentido de excluir como algo ajeno a nuestro ordenamiento jurídico, la posibilidad de controlar constitucionalmente las sentencias judiciales, so pretexto de defender la seguridad jurídica y la cosa juzgada. En múltiples oportunidades esta corporación ha indicado que existen yerros jurisdiccionales de una magnitud tal que, ante la improcedencia de recursos que corrijan la legalidad del fallo, pueden dejar al ciudadano en una situación de completo desconocimiento de su derecho fundamental al debido proceso. En estas situaciones excepcionales, resulta fundamental la intervención del juez constitucional en el marco de las competencias del juez natural. Esta corte, en sentencias W, X y Y, sostuvo ya la viabilidad excepcional de la tesis del control constitucional de las sentencias judiciales. Negar ello es tanto como desconocer el modelo filosófico de nuestro estado constitucional de derecho. Por cierto, en ningún sentido esta figura es extraña a los ordenamientos jurídicos, como podría pensarse. Países como $P, Q$ y $R$ cuentan con figuras jurídicas similares orientadas en tales sentidos".

En este párrafo — construido artificialmente, debo aclarar-, resulta fácil advertir varias intenciones comunicativas distintas, en relación con el uso de los ejemplos y de las comparaciones. La última parte en cursiva sólo pretende, si se quiere, adornar una idea. Tiene, para ser más claros, una intención retórica frente a la necesidad de abundar en argumentos en orden a darle una mejor luz a su punto, como indica Schauer. La primera parte resaltada en negrilla, a su turno, además de reforzar un argumento, intenta ofrecer una poderosa razón de orden ético acerca de las consecuencias de desconocer el tratamiento jurisprudencial de una figura jurídica en un ordenamiento. En ajustada síntesis, lo que quiere significar el juez es que resulta francamente sorprendente que el abogado desconozca esa tesis generalmente admitida, pues al hacerlo, prácticamente desco- 


\section{PRECEDENTE, ANALOGÍA Y RAZONES...}

noce el derecho en el que opera. Es incorrecto hacerlo, para decirlo contundentemente.

El uso de las sentencias W, X y Y como ejemplos y comparaciones, por el contrario, tiene un propósito diferente. Este uso, además de reforzar argumentativamente un punto, tiene fundamentalmente la finalidad de impulsar la acción; esto es, que se siga un precedente. Y junto con ello, todas las acciones accesorias que pueden eventualmente adscribírsele: que se dé por descontada una idea; que se oriente el proceso de conformidad con esa tesis; que se centre la discusión en un ámbito específico; que se desestime la improcedencia de un recuso; que el abogado acepte una tesis jurídica y la siga; y así sucesivamente.

Mucho me temo, contrario a la tesis del profesor Schauer, que el argumento por analogía es, entonces, entendido por los abogados de manera prioritaria como una comparación cuyo propósito es la extensión, hacia un evento posterior, de una regla que ha operado en un evento anterior. Esa es su fuerza ilocutiva e, incluso, su efecto perlocutivo. Es decir, la analogía no suele ser entendida por los abogados, en términos generales, como un recurso decorativo. La pregunta que se hacen en relación con las sentencias judiciales expedidas en el pasado, es si una regla que gobernó ese caso previo puede o debe hacerse extensiva en un caso posterior. Cuando ese es el propósito comunicativo, los abogados comparan de una manera distinta a cuando comparan como simple recurso retórico.

No obstante lo anterior, y aunque creo que es laborioso imaginar al interior de un proceso judicial la utilización del recurso de la comparación que no sea teniendo en la mente la extensión por vía analógica de una regla que ha operado anteriormente, podríamos concederle al argumento de Schauer que, en efecto, existirían también comparaciones con un sentido más retórico o decorativo, tal cual lo sostiene. Esto ocurre, digamos, cuando se hace referencia a una institución de derecho romano, de derecho comparado o de alguna norma jurídica derogada. Bien pueden los abogados indicar que mientras en la legislación anterior el curso debido era " $\mathrm{X}$ ", bajo los términos de la actual legislación, lo debido es hacer "Y". Este es un uso del recurso de la comparación bajo intenciones comunicati- 
vas diversas al uso del argumento analógico para seguir un precedente judicial.

Pero esto justamente demuestra que, a diferencia de lo que sostiene Schauer, una comparación o una analogía pueden tener el efecto obligatorio o vinculante según sea la intención comunicativa de quien la usa.

De modo tal que, en el mejor de los casos, podría aceptarse, en gracia de discusión, que el nombre "precedente" podría reservarse para el uso obligatorio y vinculante de las analogías, esto es, la "analogía jurídica"; mientras que el de "simple analogía" o "analogía no jurídica”, se guardaría -diríamos- para los usos retóricos o decorativos. De ser este el caso, sin embargo, lo único que podría sostener Schauer es que la "analogía no jurídica" no tiene sustancialmente nada que ver la "analogía jurídica" (precedente). Y sostener ello es avanzar muy poco, ¿verdad? Adicionalmente, la dificultad que soportaría este matiz del argumento de Schauer es que no es muy claro cómo esa elemental diferenciación, además de permitir identificar una intención comunicativa previa, pueda también alterar la estructura lógica de un recurso lingüístico — como el ejemplo o la comparación- que es por su propia naturaleza neutral. ${ }^{9}$

9 En este punto resulta de mucha importancia el buen trabajo realizado por la profesora Sandra Gómora, quien encuentra que la "ejemplaridad" es un elemento constitutivo tanto del concepto de precedente como de analogía. Aunque termina por diferenciar la fuerza normativa de las dos figuras, lo hace por una vía distinta a como lo realizan Schauer y Lamond. En su opinión, el propósito del precedente estriba en regular mediante el ejemplo, la conducta futura de los jueces. El precedente es, más concretamente, una forma comunicativa de reglas autoritativas mediante el ejemplo. Para que un caso anterior sea considerado un buen ejemplo, debe tener algún valor o relevancia atribuida que otorga su fuerza normativa (ser una buena razón para actuar), pues de lo contrario no sería tomado como una buena muestra de cómo debe decidirse. Razonar analógicamente es, por tanto, razonar mediante ejemplos, pues también de esta figura se predica la ejemplaridad. La cuestión estriba, para Gómora, en que en la analogía, la cualidad de ejemplaridad y la necesidad de adecuación (que el ejemplo sirva exitosamente a algún propósito), agotan su fuerza normativa allí, mientras que para el precedente también juega, además de estos dos elementos, el de la proyección y la autoridad (también la jerarquía). La conjugación de estas dos últimas propiedades, tornan al precedente una regla excluyente, mientras que la analogía contrae su función a la resolución de disputas parcialmente reguladas o indeterminadas, que no han sido resueltas directamente 
Pues bien, desechados estos dos primeros puntos, creo que es momento de entrar de lleno en las dos últimas distinciones analíticas que considero fundamentales.

El profesor Schauer, en un sentido especial, con su planteamiento de separar el razonamiento analógico del seguimiento del precedente, acude tácitamente a dos distintas discusiones que, para la filosofía del derecho, resultan ciertamente recurrentes. La primera de ellas corresponde a la disputa entre internalistas vs externalistas; ${ }^{10}$ vale decir, aquella que pregunta por la fuente de las razones a partir de las cuales una persona está dispuesta a actuar. La opinión de Schauer sería que la regla de seguimiento del precedente es, ante

por una autoridad legítima. La distinción conceptual que hace Gómora no la lleva, sin embargo, a nada más que a una diferencia de grados, aceptando la intrínseca relación que tienen las dos figuras, toda vez que aparecen entrelazadas cronológicamente de forma invariable. Así las cosas, el razonamiento analógico aparecería en dos momentos específicos, según nos indica: (i) como "filtro de búsqueda", ante casos parcialmente regulados o indeterminados, para "recuperar" un amplio cúmulo de ejemplos previos, dentro de lo cual pueden figurar reglas de precedente - 0 no-, así como también doctrinas, ejemplos, jurisprudencia no vinculante, etcétera; realizando con ello un balance de razones dependientes para poder fallar; (ii) con ese balance de razones, la autoridad crea la regla de precedente para el específico caso, regulándolo directamente; (ii) ante un caso posterior, análogo a este último decidido, en tanto que existe esa regla de precedente, el razonamiento analógico funcionaría para identificar el precedente vinculante que debe aplicarse. De modo que podría decirse, en opinión de Gómora, que la analogía es un elemento del precedente, pero no es todo el precedente. Aceptaré, en la misma línea en la que estoy indicando, que tanto el precedente como la analogía comparten el elemento de la "ejemplaridad", como es apenas evidente. Y también la idea implícita según la cual los ejemplos o comparaciones tienen propósitos comunicativos diversos. Eso sí, me permitiré, como se verá más adelante, separarme de Gómora, Lamond y Schauer, en el entendido de que de este punto no se sigue que la diferencia entre las dos figuras se trate de una diferencia entre razones excluyentes y razones dependientes.

10 Existe una enorme cantidad de literatura sobre esta disputa filosófica. Véase, entre otros tantos, los buenos textos de Williams, Bernard, "Internal and external reasons", Reasoning. Studies of Human Inference and its Foundations, 1981, pp. 6066; King, Patricia, "Internalismo, externalismo y autoconocimiento", Critica: Revista Hispanoamericana de Filosofía, 2000, pp. 99-119; Ortiz, Javier, “ $¿$ Puede haber razones jurídicas autoritativas?”, 1995; Redondo, María Cristina, “¿Razones internas vs. razones externas?", 1996; Bayón, Juan Carlos, “Sobre la racionalidad de dictar y seguir reglas", DOXA, núm. 19, pp. 143-162. 
ABDÓN MAURICIO ROJAS MARROQUÍN

todo, una razón externa que impone un deber; mientras que la analogía, en cambio, sería una razón interna que concierne más a las creencias y los deseos del hablante. La segunda de las discusiones gravita, con independencia de que constituya una razón externa o interna, sobre la pregunta de si, en términos de Joseph Raz, la regla del seguimiento del precedente es una razón excluyente o una razón concluyente. ${ }^{11}$ La opinión de Schauer sería que es una regla excluyente de cualquier balance de otro tipo de razones. Es decir, que existiendo ella no hace falta evaluar otro tipo de razones.

Empezaré con la primera de estas cuestiones.

\section{RAZÓN INTERNA vS. RAZÓN EXTERNA}

A pesar de que externalistas e internalistas coinciden en la idea según la cual las personas generalmente actúan porque encuentran "razones"12 para hacerlo; con todo, disienten respecto del origen o procedencia de tales razones. Así pues, los internalistas acostumbran a indicar que las razones son invariablemente "internas" al

11 La literatura sobre este particular es también extensa. Véase, entre otros muchos textos, los siguientes: Raz, Joseph, "Reasons for Action, Decisions and Norms", Mind, 84.336, 1975, PP. 481-499; Nino, Carlos Santiago, La validez del derecho, vol. 6, Astrea, 1985; Redondo, María Cristina y Navarro, Pablo Eugenio, "Normas y razonamiento práctico: una crítica a Joseph Raz”, DOXA, núm. 10, 1991, pp. 91-100; Bayón Mohíno, Juan Carlos, "Razones y reglas: sobre el concepto de «razón excluyente» de Joseph Raz”, DOXA, núm. 10, 1991, pp. 25-66; Bayón, Juan Carlos, “Sobre la racionalidad de dictar y seguir reglas", DOXA, núm. 19, 1996, pp. 143-162; Bouvier, Hernán, "Reglas y razones subyacentes”, DOXA, núm. 27, 2004, pp. 393-424; Caracciolo, Ricardo, "El concepto de autoridad normativa: el modelo de las razones para la acción”, DOXA, núm. 10, 1991, pp. 67-90.

12 A veces suele diferenciarse entre los motivos y las razones para actuar. Se supone que mientras la primera es sólo una razón aparente porque se limita a "explicar" por qué alguien pudo sentirse inclinado a actuar de determinada manera; la segunda, en cambio, "justifica” el comportamiento. Una "razón” es una justificación de la acción. Un "motivo" es una explicación de la acción. Una persona puede estar motivada a acallar violentamente a un vecino ruidoso, por ejemplo; pero según esta postura, faltan todavía razones que justifiquen la violencia ejercida por el solo hecho del ruido generado. Acallarlo violentamente sería irracional, pues no existe una justificación (razón) para hacerlo, aunque puedan existir motivos. 
PRECEDENTE, ANALOGÍA Y RAZONES...

agente que actúa, toda vez que son, después de todo, las creencias y los deseos (estados mentales, en opinión de algunos filósofos) aquellos dispositivos que mueven a alguien a comportarse de una determinada manera. Los externalistas, por su parte, sostienen que razones externas impuestas al agente, independientes de sus motivaciones, fungen como mecanismos que impulsan la acción, o al menos como motores determinantes de disposición interna del comportamiento. Por cierto, la noción jurídica de "deber" ha sido considerada paradigmáticamente un ejemplo de esto. ${ }^{13}$

En el marco de esta discusión, podría sostenerse que la opinión de Schauer se limita a indicar que cuando se propone el recurso de la analogía, el usuario de ese acto de habla se encuentra inducido

13 Cristina Redondo indica que la excepción a esta postura podría estar en cabeza de los realistas jurídicos, quienes ven al "deber jurídico" únicamente como un tema de razones internas de los operadores: son creencias las que lo mueven a actuar de una determinada manera. La apuesta realista estriba en que dichas razones internas son todo menos que razones propiamente "jurídicas", sino razones prioritariamente políticas, sociales, económicas, morales, etcétera. Igualmente, Redondo pone de presente que para algunos positivistas normativistas los deberes jurídicos no son ni razones internas ni razones externas. Frente a esto último señala que este enfoque "ha recibido fuertes críticas porque, al no admitir la relación necesaria entre deber y razón, es considerado incapaz de explicar la normatividad del Derecho". Redondo, María Cristina, “¿Razones internas vs. razones externas?”, cit., p. 136. Esta crítica también se encuentra en su texto Redondo, María Cristina, "El carácter práctico de los deberes jurídicos", DOXA, núm. 21, 1998, pp. 355-370, cuando concretamente indica que: "Un reflejo de la distinción positivista entre lo que el derecho es y lo que debe ser es la separación nítida entre los problemas de identificación del derecho, y los problemas relativos al deber de aplicación u obediencia de sus normas. Conforme a algunas propuestas positivistas... el segundo es un problema práctico que no puede ser resuelto por la teoría general del derecho... En otras palabras, el derecho no tiene por sí mismo carácter práctico, dicha cualidad depende de la corrección moral de su contenido. Desde esta perspectiva, que exista un derecho no equivale a que exista un deber de hacer lo que él establece, i.e., de obedecerlo o de aplicarlo" (p. 355). Algunos positivistas, como Raz, intentan dar cuenta de la normatividad del derecho renunciando a tomar a la clásica separación entre el derecho y la moral, como un presupuesto inherente del positivismo jurídico. Véase, por ejemplo, Raz, Joseph, "Authority, Law and Morality", The Monist, 68(3), 1985, pp. 295-324. Otros positivistas como Cristina Redondo admiten la necesidad de dar cuenta del carácter normativo del derecho sin renunciar a las separaciones clásicas del derecho con la moral, y del ser con el deber ser. 
(motivado) a actuar por cuenta de que cree que la fuente es correcta a efectos de iluminar un punto de vista (lo que presupone un internalismo). En otras palabras, la razón que mueve a un hablante - ordinario o jurídico- a usar una analogía, es la creencia de que ella servirá mejor a efectos de dar fuerza a su propósitos comunicativos y argumentativos. Por consiguiente, es una razón interna a quien la plantea. Contrariamente, actuar de conformidad con el precedente presupondría - llevando al extremo el punto de Schauerun externalismo, como quiera que una razón por fuera del agente (el deber de seguir un precedente) es la que impone un curso de acción. Acción para la cual, dicho sea de paso, resultan indiferentes las creencias y los deseos del hablante (incluso si considera equivocado la decisión anterior). En una palabra, Schauer ubicaría al precedente junto a la noción de deber, al paso que esta, siguiendo a la filosofía del derecho tradicional, es fundamentalmente una razón externa. ${ }^{14}$

Ciertamente el punto es sugestivo. No obstante, esta tesis tiene dificultades significativas. Quisiera abstenerme de entrar en profundidad sobre la discusión acerca de los presupuestos epistemológicos del externalismo, que encuentro claramente problemáticos si se toma a esta postura como algo excluyente - o al menos algo no compatible- con el internalismo. Me limitaré a enunciar algunos inconvenientes que surgen del argumento de Schauer.

En primer lugar, ¿quiere decir lo anterior, que con la asunción de que el precedente cae necesariamente en la noción externa del deber $y$, en consecuencia, que el seguimiento de un precedente no puede estar justificado por una razón interna, tendríamos que admitir que nadie podría - o debería - creer que es realmente correcto seguirlo en un determinado caso — no sólo en cuanto a la necesidad de seguirlo, sino también correcto en cuanto a su contenido-?

14 Desde este punto de vista, no es posible ubicar a Schauer dentro de los positivistas normativistas que niegan que el derecho pueda ser una razón para actuar. Todo el planteamiento de Schauer presupone la normatividad del precedente, vale decir, la capacidad de constituirse en una razón para que jueces y abogados actúen. De lo contrario, no tendría sentido diferenciar entre una acción cuya razón implícita es la necesidad de iluminar lo mejor posible un punto, versus una acción cuya razón implícita es la de "tener que" seguir un curso de acción de conformidad con el precedente, con independencia de las razones internas de quien está obligado. 
Formulo esa pregunta porque, a decir verdad, si alguien afirma estar siguiendo un precedente porque cree que es correcto su contenido, o porque seguirlo es respetuoso del derecho a la igualdad con independencia de su contenido, es bastante evidente que está, en ambos casos, expresando una razón interna. De tomarnos el punto de Schauer en serio, en cambio, tendríamos que estar dispuestos a aceptar las siguientes dos tesis:

a) Toda referencia a una razón interna para seguir un precedente comete un error técnico. Repárese en las siguientes dos afirmaciones: (i) "debemos seguir el precedente X porque fue la decisión correcta para este tipo de casos"; y (ii) "debemos seguir el precedente $\mathrm{X}$ porque debemos respetar los principios de igualdad, seguridad jurídica y coherencia interna del ordenamiento". De conformidad con este primer punto de vista, los dos son enunciados mal redactados o mal expresados. Lo que en puridad debió decirse fue: "debemos seguir la sentencia X porque es el precedente obligatorio, con independencia de si la considero correcta y además compatible con los principios de igualdad, seguridad jurídica y coherencia interna del ordenamiento". De hecho, la última parte resaltada tendría que sobrar, pues nada quita o agrega. ${ }^{15}$

Al mismo tiempo, la expresión "quisiera iluminar lo mejor posible mi punto de vista en el sentido de señalar que la norma $\mathrm{X}$ es la que se impone para el caso actual, poniendo de presente, apenas como un ejemplo orientador, al precedente A", sería también un enunciado anti-técnico, como quiera que las expresiones "precedente" y "ejemplo orientador" no pueden ir conjuntamente.

b) 0 puede ocurrir que el hablante que recurre a razones internas para justificar el seguimiento de un precedente, no ha advertido todavía que lo que verdaderamente lo mueve es una razón externa. 0 habiéndolo advertido, quiere deliberadamente falsear su razón externa bajo el ropaje mendaz de una razón interna.

Subsiste la pregunta sobre qué lo hace obligatorio. Ya me detendré en ese tema. 
Por consiguiente, se trataría de una ingenuidad o una deshonestidad psicológica.

Puede advertir el lector que estas son teorías manifiestamente engañosas. Quiero decir, psicológicamente engañosas: ¿Cómo podría negarse la posibilidad real de que razones internas muevan a los juristas a seguir los precedentes? ¿Qué prueba podríamos ofrecer para cerciorarnos de que ello nunca ocurre? ¿Cómo podría probarse una deshonestidad psicológica, acaso? En cierto sentido, estas tesis violentan también los principios de colaboración y de caridad lingüística, a partir de los cuales no deberíamos atribuir o suponer en el hablante todas nuestras creencias, al momento de interpretarlo, a tal punto que desaparezca la diferencia entre el hablante y el intérprete; ni deberíamos suponer que dicho hablante rompe conscientemente el principio de no contradicción.

Ahora bien, detengámonos en las siguientes expresiones: (a) "debo seguir el precedente $X$ porque los precedentes deben seguirse según lo ordena el Derecho"; (b) "debo seguir el precedente $\mathrm{X}$ porque es lo debido". Si se acoge la idea de que en relación con el seguimiento del precedente opera una razón externa (la del deber u obligación; o la remisión circular al Derecho mismo), no parece claro cómo es que, además de la simple trivialidad de que la existencia del "Derecho mismo" o estos conceptos en abstracto podrían operar como determinantes causales de un posterior estado psicológico del intérprete (razón interna), tiene por sí misma la fuerza de mover finalmente desde el punto de vista teleológico la acción. Una cosa es que una razón externa tenga una relevancia explicativa de la teleología de la acción, y otra bien distinta que justifique la acción misma. ${ }^{16}$

16 Concedo que para pensadores como Cristina Redondo existiría una razón teleológica y una razón no-teleológica como fundamento de la acción. Para la razón no teleológica (razón externa), ciertos eventos externos podrían tener una relevancia práctica directa en la acción; es decir, la podrían explicar causalmente, sin apoyo absoluto en una razón teleológica. Esto ocurre, en su opinión, cuando, por ejemplo, la sola pertenencia de un individuo a una determinada comunidad, lo lleva a reproducir ciertas acciones que la comunidad realiza espontáneamente. Según sostiene, acá este comportamiento no tiene que tener una explicación teleológica necesariamente: "no siempre se actúa en la persecución de algún objetivo. Hay acciones 
PRECEDENTE, ANALOGÍA Y RAZONES...

De hecho, para pensadores como Bernard Williams, el externalismo ni siquiera cuenta con capacidad explicativa en este sentido indicado. William es reiterativo en cuanto a la necesidad de aceptar que si una persona actúa de conformidad con una razón, esta razón debe poder explicar y justificar la acción desplegada. De este elemento carece la explicación externalista, según indica. Tomemos el ejemplo que plantea Javier Ortiz: "Supongamos que en un determinado sistema jurídico hay una norma jurídica válida que establece que los ciudadanos mayores de edad deben ingresar al ejército para prestar su servicio militar". ${ }^{17}$ Ahora pensamos en la siguiente afirmación externa: "Hay una razón jurídica para que Juan entre al ejército", con independencia de lo que él crea de ese deber. Aunque parece que esto confirmaría el punto Schauer, el externalismo tropieza con los siguientes inconvenientes:

a) Si Juan no decide ingresar, el externalismo no podría dar cuenta de la conducta de Juan por obvias razones: una creencia interna no aceptó la verdad de la afirmación externa de deber.

b) Si Juan decide ingresar, tampoco el externalismo da cuenta de qué ocurrió en Juan para que aceptara la verdad del enunciado externo y actuara de conformidad con él.

Aparentemente, entonces, sólo resta la posibilidad para que el externalismo pueda probarse, que pudiéramos constatar que Juan, sin estar motivado para ingresar al ejército, con todo lo hizo. En este punto, sin embargo, se vuelve hacia el punto "b", en el sentido de que falta una explicación de por qué se aceptó el enunciado externo como verdadero, para ingresar.

Francamente, encuentro muchas dificultades para poder ver de qué manera podría explicarse y justificarse una acción sin presupo-

que constituyen un fin en sí mismas, se realizan simplemente porque sí". Redondo, María Cristina, “¿Razones internas vs. razones externas?”, cit., p. 140. A mi modo de ver, esta afirmación es incompatible con la idea de que toda acción tiene un aspecto interno de contenido intencional. En mi opinión, no puede pasarse por alto la diferencia entre una acción automática cuya razón ha sido interiorizada o asumida mecánicamente; y una acción desprovista de razones.

17 Ortiz, Javier, “¿Puede haber razones jurídicas autoritativas?”, cit., p. 162. 
ner una razón interna, en la forma de creencias o deseos. ${ }^{18}$ Incluso cuando existe una obligación que se impone a un agente, operan en él dos creencias: (i) la creencia de que la obligación realmente existe y se reconoce como tal, y (ii) la creencia de que vale la pena en algún sentido acatarla. Y debe existir una creencia interna para poder siquiera identificarla y asumirla como una obligación externa. De lo contrario, el seguimiento del precedente o de las obligaciones jurídicas no perseguiría ningún objetivo; vale decir, no tendría ninguna teleología; no sería el medio para garantizar algo más, sino sería un seguimiento constituido en un fin en sí mismo. Sería una acción autojustificada. Y esto suena bastante extraño incluso para los sistemas de un fuerte stare decisis. ${ }^{19}$

18 Sobre este punto concuerdo con Rorty en el sentido de que haríamos bien en desechar el término "deseo" al entenderlo como una creencia más. El deseo es sólo una creencia de segundo orden, en el sentido de que presupone la existencia de otra, pero condiciona su aplicación a alguna circunstancia. De ordinario se entiende que si alguien tiene la creencia "no deberíamos matar", es de esperar que actúe de conformidad con esa creencia. Sin embargo, resulta evidente que no siempre existe coherencia entre la creencia y la acción. Por esa razón los psicólogos han indicado que entre lo uno y lo otro media "el deseo" de actuar conforme a la creencia. Rorty indica que lo que ocurre es que eso que llamamos "deseo" es una creencia del tipo "En el contexto X, lo mejor sería no aplicar la creencia A". Por ejemplo, indicando "en el contexto en donde esté en riesgo tu propia vida, lo mejor es que no apliques la creencia de "no deberíamos matar"”. Véase Rorty, Richard, (1996): «La indagación intelectual como recontextualización: una explicación antidualista de la interpretación», en Objetividad, Relativismo y Verdad, Madrid, Paidós, p. 131.

19 Como lo plantea Bouvier en la lectura que hace del texto de Schauer "las reglas en juego": "para todo caso las reglas poseen un propósito o razón subyacente que podrá ser o no tomado en cuenta al modelo que se decida adoptar. En ningún caso se prevé la posibilidad de reglas dictadas irracionalmente, a ciegas, sin conocimiento de propósitos, o sin la previsión de ciertos fines u objetivos a proteger o alcanzar. Se excluye, en definitiva, reglas sin razones subyacentes". Bouvier, Hernán, "Reglas y razones subyacentes", cit., pp. 399 y 400 . Esto es independiente de que el mismo Bouvier critique la idea de que toda regla debe perseguir un propósito. Según sostiene, esto "revitaliza" la idea del "legislador racional", lo cual encuentra empíricamente equivocado por cuenta de verdaderos "malos legisladores" que "sancionan leyes sin ningún mérito, razón o justificación". Ibidem, p. 403. En mi opinión, no puede confundirse el hecho de que exista la posibilidad de que una regla sea expedida "sin la más mínima consideración de qué estado de cosas se quería favorecer", "por error, desinterés o desconocimiento" (Ibidem, p. 400); o "sin entender 
Empero, creo que el lector ha advertido algo bastante evidente: suponiendo, en gracia de discusión, que para el seguimiento del precedente resulten realmente intrascendentes las razones internas, queda todavía la urgente tarea de determinar el significado de la expresión "deber" u "obligación", pues por ahora carecen plenamente de contenido efectivo. Ya volveré sobre este particular. Por ahora quisiera dibujar los contornos de la última de las discusiones.

\section{SEGUIMIENTO DEL PRECEDENTE Y RAZONAMIENTO ANALÓGICO: ¿RAZONES EXCLUYENTES O RAZONES CONCLUYENTES?}

Es bastante bien conocido que Joseph Raz asume, como creo que deberíamos hacerlo todos, que el lenguaje jurídico es claramente "normativo"; es decir, es un tipo de lenguaje prescriptivo de relevancia práctica, capaz de influir en el comportamiento de sus destinatarios. ${ }^{20}$ En consecuencia, Raz entiende que el lenguaje jurídico es

qué es lo que está sancionando, sin tener en cuenta las razones que favorece, o sin pensar en razón o estado de cosas alguno al cual favorecer o proteger" (ibidem, p. 403); con el hecho de que al seguir la regla deba interpretársela como persiguiendo algún fin, si quiere ser inteligible y además si quiere revestir de un carácter verdaderamente práctico. Sencillamente, cualquier agente estaría dispuesto a no seguir una regla si no asoma en ella visos de racionalidad a partir de algún propósito. Me temo que Bouvier está tomando la noción de normatividad como sinónimo de intención prescriptiva y no la está observando desde el punto de vista de su funcionalidad práctica. De este error proviene la unión de la razón subyacente de la regla a la intencionalidad que, desde luego, puede ser verdaderamente egoísta, errada o desinteresada. De ahí que él piense que no separar el "acto de la legislación" de su mérito o demérito (su razón subyacente), sería cometer la falacia naturalista. Tampoco acompaño la idea de Bouvier en el sentido de que se rompería el principio de caridad o cooperación lingüística al asumir siempre una razón detrás de una regla, porque en mi opinión suponer ello no está distorsionando el contenido intencional que tiene una determinada regla al tomarla siempre como racional, sino simplemente se está diciendo que todas ellas, si quieren ser racionales, deben tener una razón que la respalde, salvo que quiere comprometer su carácter normativo.

20 Cristina Redondo hace bien en poner de presente que existen, básicamente, dos formas de explicar la noción de "normatividad" del lenguaje jurídico. La primera de ellas entiende el carácter normativo como propiedades prescriptivas de los enunciados que se emiten "con la intención de guiar o dirigir la conducta de 
ABDÓN MAURICIO ROJAS MARROQUÍN

realmente una razón para que las personas actúen de conformidad con sus normas. Según sostiene, si las normas jurídicas no tuvieran la fuerza para hacer actuar a sus destinatarios, por cuenta de ella mismas y sin referencia a cualquier otro tipo de razones, sencillamente se perdería el carácter normativo, y habría que concluir que razones de otro tipo justifican la aplicación del derecho. Por cierto, la expresión "actuar porque el Derecho así lo ordena" dejaría de tener sentido efectivo y, con ello, el derecho se despojaría de su pretensión de ser una disciplina con relevancia práctica.

Aceptado ello, la pregunta que se formula Raz es si las normas del derecho son, como él sostiene, razones que excluyen cualquier otro tipo de razones; o si por el contrario las normas jurídicas se siguen ateniendo a un balance depurado de un conjunto más amplio de otras razones, en el que las normas jurídicas son apenas una parte; es decir, de un conjunto incluyente de más razones, respecto de las cuales se realiza un balance y una conclusión. Si el argumento de Raz es correcto, tiene razón Schauer: el precedente, a partir de su mera existencia, es una razón en sí misma para que se siga, con independencia de cualquier otro tipo de razones. La analogía, en cambio, surgiría del balance de razones, y estas sí son internas al agente. ${ }^{21}$

otro agente", esto es, enunciados que contienen términos deónticos de acuerdo a la intención de quien los emite. La segunda, en cambio, toma el carácter normativo como una propiedad de los enunciados que tienen "relevancia práctica", es decir, que se constituyan en verdaderas razones para actuar. Redondo correctamente descree de la primera de dichas nociones por cuanto, de ser cierta, tendríamos que admitir, por ejemplo, que el "Derecho Romano" es todavía normativo a pesar de que parece claro que, al día de hoy, carecen sus disposiciones de normatividad. Redondo, María Cristina, "El carácter práctico de los deberes jurídicos", cit., pp. 355-370.

21 Esta es, en mi opinión, la tesis que sostiene Lamond. Para él, la analogía "complementa" al precedente cuando el caso presente no cae dentro de la sombra de irradiación de la sentencia vinculante anterior. Para Lamond, el argumento analógico tiene una fuerza normativa diferente del precedente, dado que sobre este último el curso de acción debido es su anulación (por un tribunal superior), su distinción o su seguimiento irremediable. La analogía, en cambio, es apenas una buena razón para orientar una decisión judicial actual, que puede ser "cercana" (si apoya intensamente un resultado) o "lejana" (si apoya débilmente un resultado). En consecuencia, las analogías no vinculan y deben ser balanceadas con otras razones para llegar a un determinado resultado. Lamond, Grant, op. cit., pp. 17 y ss. De acuerdo con mi interpretación, la tesis de que el precedente es una regla excluyente, mientras que 
PRECEDENTE, ANALOGÍA Y RAZONES...

Pues bien. El modelo que acoge Raz para dar cuenta de la normatividad del derecho es el de las razones excluyentes (RE), que entiende como algo sustancialmente diferente al modelo del balance de varias razones de primer orden (BRPO) ${ }^{22}$ que son medidas más por su peso, fuerza o importancia, de conformidad con alguna escala que asumirá quien realice la estimación de todas ellas.

Sin embargo, como es ya un lugar común en las lecturas a la propuesta de Raz - y como el mismo autor reconoce-, es necesario aceptar que la razón excluyente, en tanto que razón que excluye las demás razones, si quiere ser considerada racional y, por tanto, admisible, debe ella misma provenir de una razón que la justifique. Como plantean Cristina Redondo y Pablo Navarro, deben existir argumentos que permitan diferenciar entre una RE justificada y una RE injustificada. Y esta razón justificativa de la RE, dado que implica cotejar razones, proviene de un BRPO. Por consiguiente, las RE y las RRPO no son independientes. Por el contrario, este último modelo justifica al primero. ${ }^{23}$

Esto mismo ocurre con el seguimiento del precedente, en mi opinión. Aun si asumiéramos que la regla del seguimiento del precedente obedece a una RE, y aún si asumiéramos incorrectamente que las RE son al mismo tiempo razones externas; de cualquier modo su justificación y aceptación debe provenir de un cotejo o balance de otras razones. Y, como se dijo más arriba, parece bastante evidente que un balance de razones sólo puede tener ocasión como un balance interno de razones. Es decir, es el agente quien de conformi-

la analogía siempre procede de un balance de razones dependientes, es también la tesis que sostiene Sandra Gómora. Véase Gómora, Sandra, op cit.

22 Se les llama de primer orden porque a partir de ellas se produce la razón de actuar. En consecuencia, la razón por la cual actúa el agente ocupa un lugar lógicamente posterior al de las razones que fueron objeto de balance. Así las cosas, si A, B y $\mathrm{C}$ son razones que deben ser balanceadas, la razón concluyente tendrá la forma de "debemos hacer A, consideradas todas las razones". Sobre las razones excluyentes en el pensamiento de Raz, puede consultarse: Vega Gómez, Juan, "El positivismo excluyente de Raz", Boletín Mexicano de Derecho Comparado, nueva serie, año XXXVII, núm. 110, mayo-agosto de 2004.

23 Redondo, María Cristina y Navarro, Pablo Eugenio, “Normas y razonamiento práctico: una crítica a Joseph Raz", cit., p. 95. 
dad con alguna escala de peso, fuerza o importancia, estimará cuál razón debe triunfar a efectos de poder actuar. De modo que no existe la diferencia entre el seguimiento del precedente y el razonamiento analógico que sugiere Schauer. ${ }^{24}$

Sospecho que el lector, como yo, dudaría de la idea de que las RE puedan ser consideradas, ni siquiera en la versión radical de Raz, como razones necesariamente impuestas externamente al agente. Y esto resulta más claro atendiendo al punto que Redondo y Navarro ponen de presente, correctamente en mi opinión: si las normas jurídicas son, por definición, RE, entonces resulta bastante claro que no podrían existir normas jurídicas que no se siguen. ${ }^{25}$ No seguirlas implicaría aceptar que otra razón operó y, por cierto, excluyó la razón excluyente. Y excluir la RE es lo mismo que decir que no funcionó como RE. Y esto, a su turno, supone que es la aplicación y no la existencia el criterio de identificación de una RE:

Raz sostiene que las [RE] son aquellas razones que funcionan excluyendo el balance de razones, y si las normas funcionan de este modo sólo cuando el agente las acepta y las sigue, entonces Raz debe admitir que una norma es una [RE] sólo cuando es aceptada y seguida por

24 Según el ejemplo de Lamond, "los cuchillos pueden ser análogos a las pistolas si el problema se refiere a las armas, pero los cuchillos pueden ser análogos a las cucharas, si el problema se refiere a los cubiertos". De modo que, en su opinión, la fuerza normativa de la analogía depende fundamentalmente de la justificación específica que tenga para un caso determinado, el ejemplo anterior. Los casos no son análogos en abstracto sino en el contexto específico de la cuestión jurídica planteada, nos dice. Cuanto más abstracto sea su uso, menor será su fuerza normativa. Cuanto más concreto, mayor. Según Lamond, la analogía tiene el propósito de dar a conocer al juez una variedad más amplia de casos y hechos, cuando existe la necesidad de "profundizar y agudizar" la reflexión, cuando no se comparte una perspectiva normativa uniforme, para "compensar parte de la indeterminación" de los materiales jurídicos. Es extraordinariamente extraño suponer que nada de ello ocurre con el precedente. La diferencia, así planteada, sería tan excepcionalmente trivial como lo es decir que en el precedente operaría una especie de presunción de seguimiento, salvo la distinción o la anulación (que provienen claramente de un balance de razones); mientras que en la analogía operaría un balance de razones directo, no intermediado por la presunción. Lamond, op. cit.

25 Piénsese en el fenómeno de la "derrotabilidad" de las normas o de la "distinción", que desaparecerían por completo. 
el agente. Por lo tanto, es la aceptación y no la existencia de la norma, lo que constituye la [RE] para la acción. Sostener que la RE es el hecho de que la norma exista, con independencia de su aceptación, exige señalar una propiedad que permita identificar ese tipo de razones. De no ser así, Raz debe admitir, o bien que la aceptación es lo que constituye la [RE], o que la existencia de las normas consiste en que ellas son aceptada y seguidas. En ambos casos queda expuesto a la misma crítica que le formulara a Hart: no poder explicar las normas con independencia de su práctica. ${ }^{26}$

Este argumento debería ser particularmente preocupante para Schauer, porque entonces es la aceptación y no la existencia del precedente lo que puede constituir una razón excluyente para actuar de conformidad con él. Y, desde luego, la aceptación implica un balance interno de razones: "aceptar una norma es creer que hay razones para seguirla, es tener una razón operativa para hacerlo". ${ }^{27}$ Naturalmente, seguir un precedente por cuenta de su sola existencia, conllevaría seguirlo sin consideraciones adicionales, menos aún si ellas se orientan en contravía del curso de acción del caso anterior. De modo que incluso concediendo la existencia de un principio hermenéutico del tipo "debes siempre y de forma excluyente seguir los precedentes", para que pueda ser entendido como una RE, debe justificarse en un balance previo de razones. Y si este balance arroja el resultado de que no será excluyente para un determinado caso, desaparece la obligatoriedad excluyente que encuentra Schauer en el precedente a diferencia de la analogía. Y nuevamente, su diferencia ha sido diluida.

Ahora bien, Juan Carlos Bayón ha dejado ver en algunos de sus textos ${ }^{28}$ que Raz podría estar dispuesto a aceptar que tomar a las reglas como RE puede ser "irracional" en condiciones ideales del discurso, situación en la cual se cuenta con tiempo e información suficiente para realizar siempre un balance ordenado y depu-

26 Redondo, María Cristina y Navarro, Pablo Eugenio, “Normas y razonamiento práctico: una crítica a Joseph Raz", op. cit., p. 96.

27 Ibídem, p. 97.

28 Bayón, Juan Carlos, "Sobre la racionalidad de dictar y seguir reglas”, DOXA, núm. 19, pp. 143-162. 
rado de razones. En dichas circunstancias, un RE generaría, ciertamente, decisiones subóptimas. Sin embargo, a falta de este contexto ideal, en las situaciones reales de deliberación y de definición sobre lo que debe hacerse, la RE funge óptimamente como razón pragmática que ahorra tiempo, trabajo, frustración, y además maximiza otras tantas cosas, "postergando" el propio juicio para dejar en manos de las autoridades "expertas" el balance de razones. ${ }^{29}$ De manera que la RE sería algo así como la conclusión de un balance previo de razones que la autoridad realizó con antelación, pero que el usuario de la regla usa ya como RE para evitar tener que hacer él mismo su propio balance. Por cierto, para Raz no tomarla de este modo desconocería el concepto mismo de "autoridad", cuyo sentido parece construirse a partir de la idea de una obediencia no condicionada a balances de sus destinatarios.

Es bastante evidente, no obstante ello, que para que un usuario de una regla tenga semejante juicio (ahorrar tiempo, dejar todo en manos expertas, evitar frustraciones y trabajo), debió realizar un balance de razones cuya conclusión fue, justamente, tomar de ahí en adelante a las reglas de la autoridad como razones excluyentes. Es decir, tuvo que encontrar buenas razones para postergar su propio juicio y dejar todo en manos de la autoridad en la que confía. Y, adicionalmente, como bien indica Bayón, debe decirse que "si aceptar una autoridad es aceptar sus reglas como razones excluyentes..., entonces la práctica de la autoridad simplemente no puede tener lugar entre sujetos racionales". ${ }^{30}$

Ahora bien, en este punto podrían lanzarse algunos conocidos salvavidas sobre la propuesta de Raz acerca de las RE. Podría indicarse, por ejemplo, que sería una gruesa confusión sostener que Raz entiende a las RE como razones absolutas (RA), esto es, como razones que deben triunfar siempre, en todo caso, en el entendido de que

29 Sobre la postergación del juicio y la paradoja de la irrelevancia moral de la autoridad pueden consultarse, además de los textos de Raz, a Bayón, Juan Carlos: "Razones y reglas: sobre el concepto de «razón excluyente» de Joseph Raz", DOXA, núm. 10, 1991, pp. 25-66; y Nino, Carlos Santiago, El constructivismo ético, Madrid, Centro de Estudios Constitucionales, 1989.

30 Bayón, Juan Carlos, "Sobre la racionalidad de dictar y seguir reglas", op. cit., p. 149. 
no existe una circunstancia que la sobreponga. ${ }^{31} \mathrm{Y}$, en especial, se diría que Raz no las encuentra propicias para explicar el mundo del Derecho, toda vez que ello supondría la existencia de una autoridad con un poder excepcional no tolerable por ningún sistema jurídico. Puede advertirse que al indicar que las RE no siempre excluyen, porque no son absolutas, se pierde buena parte de la propiedad de obligatoriedad cuya fuerza normativa distinguiría a los precedentes. La pregunta que surge inmediatamente es bajo qué criterios, entonces, la RE se relativiza. Y, desde luego, qué otras razones entran en juego para relativizar la RE, y por qué tienen un peso mayor que la RE. Otras razones que, por supuesto, deberán también que balancearse.

Ahora bien, un segundo salvavidas se orientaría hacia la idea de que la noción de RE no elimina o hace desaparecer las razones de primer orden en las que ella se basa. Lo que implica la RE es la pretensión de dejar de considerarlas directamente como una razón para la acción (que no sean ellas las que motiven realmente la acción compliance-), que es algo distinto a negar que luego la razón de primer orden y la razón excluyente, se puedan corresponder - conforming-. Veamos un ejemplo: las razones A, B y C resultan balanceadas por la autoridad J. Dicha autoridad dispone que la razón para actuar debe ser A, que conduce a la conducta X (si hubiera elegido B o C, la conducta sería distinta). Cuando alguien se pregunte si debe desplegar o no la conducta $\mathrm{X}$, lo deberá hacer por cuenta de que ya la autoridad J prescribió F: "debe hacerse X", conforme a un balance previo que realizó basado en $\mathrm{A}$.

Es decir, ante la alternativa de basarse en A directamente bajo su propio balance, o basarse en $\mathrm{F}$, el destinatario elegirá $\mathrm{F}$ para realizar $\mathrm{X}$, porque así lo dispuso la autoridad, quien le ahorra tiempo, le evita frustraciones y trabajo. ${ }^{32} \mathrm{Y}$ además porque si no fuera así, dice Raz, la falta de coordinación podría dar al traste con el seguimiento mismo del derecho. Repárese, en consecuencia, en que realizado X,

31 Raz, Joseph, Practical Reasons and Norms, Oxford, Oxford University Press, 1999, p. 27.

32 En este punto entran en juego las famosas tesis de la dependencia, de la justificación y de la exclusividad, que no es el caso por ahora explicarlas en mayor detalle. 
concurren tanto la razón A como la razón F. Por consiguiente, la RE no excluye las razones de primer orden que, para este ejemplo, era A. De hecho, la razón A estaría "protegida" por la RE.

¿Pero decir eso no es una obviedad? Es muy evidente que la RE no elimina la razón de primer orden en la que se basa la autoridad, puesto que de hacerlo, la RE implicaría el mandato de obedecer ciegamente a la autoridad que expide reglas sin razones. Y esto tampoco sería tolerable, pues se trataría de una autoridad de facto y no una autoridad legítima. Se sabe perfectamente que la autoridad tuvo alguna razón dependiente para expedir F. Pero si es cierto el esquema de Raz, como aparentemente lo lee Schauer, entonces debería ser indiferente para el destinatario saber cuál es esa razón de primer orden en la que se basa F. Y, por cierto, debería ser indiferente también el hecho de que, al hacer $\mathrm{X}$, la razón $\mathrm{F}$ concurra con la razón A o con cualquier otra que hubiera podido conducir también a $X$. En ese sentido, una cosa sería saber que existe una razón dependiente en la que se basa la RE, que no se elimina; otra conocerla; y otra bien distinta, aceptarla.

Lo que resulta particularmente curioso es que podamos suponer que así funciona operativamente el seguimiento de los precedentes judiciales. De acuerdo con Raz y con quienes insisten en que el precedente es una RE distinta sustancialmente al razonamiento analógico, sostienen al mismo tiempo que una autoridad sería considerada legítima si las reglas que expide son válidas y vinculantes, con independencia del contenido de la regla. Además de ser extraordinariamente extraño suponer que los jueces no están interesados en hacer explícitas - y buscar la legitimidad de su autoridad, justamente en- las razones dependientes en las que se basa; está la pregunta sobre qué pasaría si advertimos que la regla dependiente es ilegítima e incorrecta. No es cierto que la RE la blinde o proteja. ¿Podría, acaso, una autoridad judicial dictar cualquier tipo de RE? Es bastante claro que no, conforme se explicó más arriba. Y al mismo tiempo, ¿cómo podría acaso determinarse y seguirse un precedente, si la RE que lo produce no se formula y se acepta en términos de las razones dependientes en las que se basa?

Como consecuencia de lo anterior, ninguno de los dos anteriores salvavidas, en mi opinión, funcionan para darle una fuerza norma- 
tiva diferente al precedente respecto de lo que ocurre con el razonamiento analógico. Y no debe olvidarse que en este escrito no se quiere negar que en las analogías realizadas por los juristas, casi siempre esté una razón adicional a considerar en el balance (la de la autoridad). Lo que se está indicando es que si la diferencia entre la analogía y el precedente corre por cuenta del supuesto hecho de que en el primero existe un balance de razones y en el segundo no, el soporte de la diferenciación parecería fracasar.

\section{LA OBLIGATORIEDAD DEL PRECEDENTE Y LA “VERDAD" COMO RAZÓN PARA SEGUIRLO}

Si seguimos a Bernard Williams, ${ }^{33}$ la racionalidad de las acciones depende de que ellas provengan de razones que las justifiquen, y que no sólo las expliquen. Según una bastante conocida indicación que hace, si alguien tiene una creencia falsa, y actúa de conformidad con ella, lo que ocurre es que él suponía tener razones; pero, con todo, sólo tenía motivos para actuar. Quiere con ello indicar Williams que la característica racionalizadora de la creencia como razón interna para la acción presenta dos niveles: en primer lugar, una creencia sirve para explicar teleológicamente una acción, es decir, para motivar el comportamiento. En segundo lugar, si dicha creencia ha sido forjada o "fijada" — siguiendo el lenguaje de Peirce- ${ }^{34}$ a partir de un proceso de deliberación por medio del cual el agente elige esa específica creencia por sobre otras, depurándolas, se ha pasado de la simple motivación interna, a la acción propiamente racional (en eso consiste el "balance" de razones). Williams considera que el principal proceso de depuración consiste en la identificación de sus creencias verdaderas y falsas para, por ese camino, concluir lo que más arriba ya se dijo: si se tiene efectivamente una razón para actuar o sólo se creía tener una razón para ello.

33 Williams, Bernard, “Internal and External Reasons”, Moral Luck: Philosophical Papers 1973-1980, Cambridge University Press, 1981, pp. 101-113.

34 Peirce, Charles Sanders, "La Fijación de la Creencia", en Charles S. Peirce. El hombre, un signo (El Pragmatismo de Peirce), Barcelona, Crítica, 1988, pp. 175-199. 
Al margen de si lo anterior ocurre siempre, lo cierto es que a veces el sentido racional de la acción depende del hecho de que el agente encuentre verdadera la creencia que la respalda. Otras tantas veces no es así, desde luego. Alguien puede, por ejemplo, encontrar sentido en el efecto de lo expresado, en vez de en el significado verdadero de la expresión. Quien bromea en sus reuniones sociales jamás encuentra una razón para hacerlo en la verdad de lo que dice, por ejemplo.

En lo que a este escrito interesa, sospecho que resulta necesario diferenciar entre la regla que obliga a seguir los precedentes (ROSP) y la regla del precedente (RDP), a efectos de evitar más confusiones. En mi opinión, la regla que obliga seguir a los precedentes (ROSP), como lo señalé en las líneas anteriores, también es una razón interna e igualmente proviene del balance de razones. Ahora lo que quisiera sostener es que, adicionalmente, el balance de razones para aceptar la regla que ordena seguir el precedente judicial, dependería o se condicionaría, a su turno, a la verdad de la regla del precedente (RDP). Es decir, la verdad de la RDP podría ser parte fundamental del balance de razones para aceptar y seguir la ROSP. ${ }^{35}$ No obstante, no siempre ocurre ello:

Quien propone una fuente o candidata a precedente en un determinado pleito, puede estar más cerca de encontrar sentido racional a seguirla, por cuenta del carácter veritativo de la regla jurisprudencial, con independencia de que se entienda por "verdad", a su turno, algo interno o externo al individuo. ${ }^{36} \mathrm{Al}$ mismo tiempo, quien debe acatar la fuente que no ha elegido, podría estar más cerca de encontrar el sentido a su acción en virtud de creencias internas sobre la

35 Esto supone separarse radicalmente de la tesis según la cual una regla puede determinarse, entenderse y seguirse con independencia de su contenido, como se pretende establecer para la RE.

36 Esta es una discusión enorme de la epistemología. La teoría de la verdad como correspondencia con el mundo, es una teoría que, a pesar de que se encuentre en mi opinión cada vez más desacreditada académicamente, representa el modelo paradigmático de verdad como algo externo. A su turno, un cúmulo importante de teóricos indican con buenos argumentos que la verdad es prioritariamente un tema interno al lenguaje, y que el "mundo" sólo tiene relevancia epistémica cuando ha sido nominalizado. 
PRECEDENTE, ANALOGÍA Y RAZONES...

coherencia del sistema, la seguridad jurídica, la igualdad, etcétera. Sin embargo, creo que pueden acontecer seis variantes perfectamente identificables, en el marco de dichos extremos:

1) Que alguien que propone una fuente o candidata a precedente, le encuentre sentido a seguir la regla allí contenida por razones de coherencia, seguridad jurídica o igualdad, entre otras; y no porque encuentre verdadera la regla jurisprudencial. En este caso, es un balance interno de razones sobre la ROSP y no sobre la RDP, la que constituye la razón para actuar.

2) Que alguien que propone una fuente o candidata a precedente, le encuentre sentido a seguir la regla allí contenida porque la encuentra correcta, con independencia de la coherencia con el resto del sistema jurídico, la seguridad jurídica o la igualdad. En este caso, es un balance interno de razones sobre la RDP y no sobre la ROSP, la que constituye la razón para actuar.

3) Que alguien que propone una fuente o candidata a precedente, le encuentre sentido a seguir la regla allí contenida porque la encuentra correcta, al tiempo que encuentra correcto seguirla por razones de coherencia con el resto del sistema jurídico, seguridad jurídica y respeto de la igualdad. En este caso, es un balance interno de razones tanto de la ROSP como de la RDP, la que constituye la razón para actuar.

4) Que alguien que debe acatar una fuente que no ha elegido, encuentre de cualquier modo sentido a seguirla por razones de coherencia, seguridad jurídica o igualdad; y no porque encuentre verdadera la regla jurisprudencial. En este caso, es un balance interno de razones sobre la ROSP y no sobre la RDP, la que constituye la razón para actuar.

5) Que alguien que debe acatar una fuente o candidata a precedente que no ha elegido, de cualquier modo le encuentre sentido a seguirla porque la encuentra correcta en cuanto a su contenido. En este caso, es un balance interno de razones sobre la RDP y no sobre la ROSP, la que constituye la razón para actuar.

6) Que alguien que debe acatar una fuente o candidata a precedente que no ha elegido, de cualquier modo le encuentre sentido a seguir la regla allí contenida porque la encuentra co- 
ABDÓN MAURICIO ROJAS MARROQUÍN

rrecta, al tiempo que encuentra correcto seguirla por razones de coherencia con el resto del sistema jurídico, seguridad jurídica y respeto de la igualdad. En este caso, es un balance interno de razones tanto de la ROSP como de la RDP, la que constituye la razón para actuar.

Ya se dijo que para Schauer la ROSP sería comprensible únicamente como una razón externa y excluyente, a partir de lo cual nadie que propone o acata una RDP puede tener razones para seguirla distintas de las razones que ya encuentra en la ROSP. Pero esto tiene dos problemas evidentes: en primer lugar, la RDP resulta, entonces, plena y absolutamente indiferente; en segundo lugar, no existirían ni lógica ni fácticamente posibilidades para no seguir la RDP. ${ }^{37} \mathrm{Nue}-$ vamente: no seguir un precedente sería siempre irracional. ${ }^{38}$

Y esto es, desde luego, contraintuitivo. En términos generales los jueces y los abogados acuden, precisamente y de forma significativa, a la verdad o corrección de una RDP tanto para seguirla como, en ausencia de ello, para no seguirla. Y este balance suele ser incluso más poderoso que el balance sobre la ROSP. En otros términos: un usuario regular de los precedentes puede haber concluido, en términos generales, luego de realizar un balance sobre la igualdad, la seguridad jurídica y la coherencia del sistema, que vale la pena en lo posible obedecer la regla que ordena seguir el precedente; y aun así luego desistir de aplicarla porque el nuevo balance sobre la regla del precedente (su ausencia de verdad o de corrección), así lo obliga.

37 Es de entrada problemático pensar que no podrían existir razones internas para que un precedente no se acate, toda vez que no es claro cómo podría controlarse el sistema de creencias de los operadores jurídicos para cerrar el paso a una creencia (o balance de razones) que desafíe el seguimiento de un precedente. De seguir el argumento de Schauer, cuando una Corte varía un precedente, lo que ha ocurrido en realidad es que actuó sin razón alguna; actuó ciegamente, incluso cuando ha advertido la falta de racionalidad de su conducta. Esta es una forma bastante extraña de describir el proceso de transformación del derecho.

38 Me parece correcta la afirmación de Bayón en el sentido de decir que "si un agente aprecia que lo debido, todas las cosas consideradas, no coincide con lo exigido por una regla y no obstante decide seguirla, su decisión sólo puede ser calificada como el producto de una irracional reverencia hacia la regla". Bayón, Juan Carlos, "Sobre la racionalidad de dictar y seguir reglas", op. cit., p. 145. 
Parecería, entonces, que el balance de la RDP tiene una mayor fuerza que el balance de la ROSP.

En este punto debe ya estar muy claro para el lector que la RE que Schauer eventualmente encontraría en la ROSP, acude en forma vacía a la noción de "deber", pues ese concepto funciona normativamente tanto para informar "cómo debe actuarse" como para informar "cómo no debe actuarse": no es un deber por un deber, sino que debe existir una propiedad o criterio a partir de lo cual el agente esté capacitado para decidir que, estando la propiedad presente debe hacer lo que la regla indica; o que a falta de ello debe abstenerse de actuar en dicha forma. De lo contrario, la expresión "deber", sin contenido alguno, implicará una obligación ciega en relación con la acción. Es decir, una acción desprovista de razones. ${ }^{39}$ Es bastante evidente, por lo demás, que la noción de "deber" puede ser también entendida como sinónima de una razón para actuar, que en absoluto excluye el balance de razones.

Debo admitir que en algunos apartados Schauer varía el criterio de la existencia del precedente, y lo transforma en un criterio de identidad entre casos. Por ejemplo, señala que cuando la "identidad entre una decisión anterior y una cuestión actual es obvia e inescapable, entonces el precedente impone una restricción diferente del efecto típico del argumento por analogía" (Schauer, 2008, p.454 y 458). Es decir, la regla que obliga a seguir el precedente (ROSP) se activa, diríamos, una vez que se constata la identidad (¿conceptual? ¿fáctica?) entre el caso anterior y el caso nuevo. Pero si esto es correcto, entonces la ROSP jamás podría ser una regla excluyente, toda vez que no es ella misma sino el producto de un balance sobre otro tipo de razones la que entrega su normatividad. La ROSP es una regla dependiente de una conclusión previa. Después de todo, sí es entonces el contenido de la RDP la que determina su fuerza jurídica.

39 Como sostiene Bayón: "Un agente verdaderamente racional no puede en ningún caso aceptar reglas como razones excluyentes. Eso es tanto como decir que un agente racional nunca queda eximido de componer el balance de todas las razones en juego y de actuar con arreglo al resultado del mismo". Bayón, Juan Carlos, "Sobre la racionalidad de dictar y seguir reglas", op. cit., p. 144. 
Y en este preciso momento cobra sentido preguntarse lo siguiente: dado que la razón para tomar a la ROSP como una RI y una RE, es el hecho de que se constate la identidad entre los casos, queda todavía absolutamente todo por decir en relación con el modo de definir dicha identidad, así como las discusiones sobre la verdad de ese modelo de su fijación.

\section{CONCLUSIONES}

Creo entonces, como consecuencia de todo lo anterior, que los presupuestos utilizados por el profesor Schauer para separar el uso y seguimiento del precedente, de la estructura de la analogía, son al menos problemáticos. Al día de hoy, realmente no existen razones suficientes que lleven a modificar el esquema analógico operativo de muchos sistemas jurídicos para los cuales el uso del precedente es fundamental. En otro trabajo he intentado defender la reformulación metodológica que, en mi opinión, debería darse para trabajar de una mejor manera con las analogías jurisprudenciales. Para ello he tomado como base los ya viejos y clásicos conceptos de fuerza ilocutiva y efecto perlocutivo a efectos de poder distinguir entre un problema de determinación del significado de un precedente, por un lado, y un problema de seguimiento de dichos significados, por el otro. ${ }^{40}$ Sin embargo, a este y otros trabajos similares de otros autores se les ha puesto la difícil tarea de reconsiderar el hecho de que el seguimiento del precedente sea algo realmente inscrito en el marco lógico del recurso de la analogía. Este texto intenta contribuir en ese camino.

\section{REFERENCIAS}

BÄCKER, Carsten, "Reglas, principios y derrotabilidad”, DOXA, Cuadernos de Filosofía del Derecho, num. 37, 2014. 
BAYón, Juan Carlos, "Razones y reglas: sobre el concepto de «razón excluyente» de Joseph Raz", DOXA, núm. 10, 1991.

BAYón, Juan Carlos, "Sobre la racionalidad de dictar y seguir reglas", DOXA, núm. 19, 1996.

Bouvier, Hernán, “Reglas y razones subyacentes”, DOXA, núm. 27, 2004.

CARACCIOLO, Ricardo, "El concepto de autoridad normativa: el modelo de las razones para la acción”, DOXA, núm. 10, 1991.

GómorA Juárez, S., "La ejemplaridad y proyección del precedente", Problema. Anuario de Filosofía y Teoría del Derecho, núm. 12 2018.

GUASTINI, Riccardo, Interpretar y argumentar, Centro de Estudios Políticos y Constitucionales, 2014.

KING, Patricia, "Internalismo, externalismo y autoconocimiento", Crítica: Revista Hispanoamericana de Filosofía, núm. 96, 2000, .

LAMOND, Grant, "Precedent and Analogy in Legal Reasoning", en Zalta, Edward N. (ed.), The Stanford Encyclopedia of Philosophy, Spring 2016 Edition, disponible en: https://plato.stanford.edu/archives/spr2016/entries/legal-reas-prec/.

Nino, Carlos Santiago. La validez del derecho, Buenos Aires, Astrea, 1985, vol. 6.

Nino, Carlos Santiago. El constructivismo ético, Madrid, Centro de Estudios Constitucionales, 1989.

ORTíz, Javier: ¿Puede haber razones jurídicas autoritativas?, ISONOMÍA. Revista de Teoría y Filosofía del Derecho, núm. 3, 1995.

Peirce, Charles Sanders, "La fijación de la creencia”, en Peirce, Charles S., El hombre, un signo (El Pragmatismo de Peirce), Barcelona, Crítica, 1988.

RAZ, Joseph, "Authority, Law and Morality", The Monist, 68(3), 1985. RAZ, Joseph, "Reasons for Action, Decisions and Norms", Mind, 84(336), 1975.

RAZ, Joseph, Practical Reasons and Norms, Oxford, Oxford University Press, 1999. 
Redondo, María Cristina, ¿Razones internas vs. razones externas?, Isonomía. Revista de Teoría y Filosofía del Derecho, núm. 4, 1996.

Redondo, María Cristina, “El carácter práctico de los deberes jurídicos”, DOXA, núm. 21, 1998.

Redondo, María Cristina y Navarro, Pablo Eugenio, "Normas y razonamiento práctico: una crítica a Joseph Raz”, DOXA, núm. 10, 1991.

RodríGuEz, J. A. S. y Rivas, P., El último eslabón del positivismo jurídico: Dos estudios sobre Joseph Raz, Granada, Comares, 2005.

RojAs MARroquin, Abdón, "La fuerza ilocutiva y los efectos perlocutivos en el análisis estático de sentencias judiciales", Revista de Derecho (Valdivia), 30(2), 2017.

RoRTY, Richard, "La indagación intelectual como recontextualización: una explicación antidualista de la interpretación”, Objetividad, relativismo y verdad, Madrid, Paidós, 1996.

SchaUer, Frederick, "Precedent", Stanford Law Review, 1987.

Schauer, Frederick, Las reglas en juego, Madrid, Marcial Pons, 2004.

SchAuER, Frederick, "Has Precedent Ever Really Mattered in the Supreme Court”, Ga. St. UL Rev., 24, 2007.

SchAuER, Frederick, "Why Precedent in Law (and Elsewhere) is not Totally (or even Substantially) about Analogy", Perspectives on Psychological Science, 3(6), 2008.

Schauer, Frederick, The Force of Law, Harvard University Press, 2015.

VEGA Gómez, Juan, "El positivismo excluyente de Raz", Boletín Mexicano de Derecho Comparado, nueva serie, año XXXVII, núm. 110, mayo-agosto de 2004.

Williams, Bernard, "Internal and External Reasons", Moral Luck: Philosophical Papers 1973-1980, Cambridge University Press, 1981. 